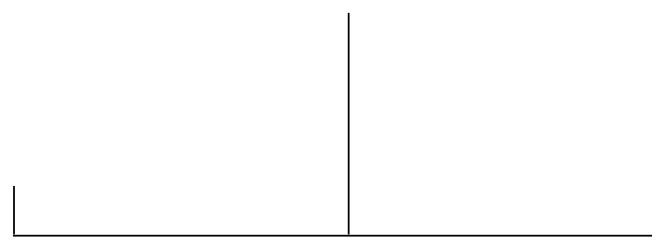

Rev. Latinoam. Psicopat. Fund., São Paulo, v. 15, n. 2, p. 404-412, junho 2012

\title{
Uma visita ao Asilo de Pedro II no Rio de Janeiro, Brasil (1880)*
}

François Jouin

Encarregados de uma viagem profissional médica a bordo do vapor Belgrano, da companhia dos carregadores reunidos, pudemos visitar a costa leste da América do Sul e relatar, a partir das nossas peregrinações, algumas noções interessantes sobre a patologia geral das afecções mentais dessas regiões, bem como sobre o funcionamento dos seus asilos.

Para não nos repetir e por não termos observado nada de especial no sentido científico nos asilos de Montevidéu e de Buenos Aires, falaremos aqui apenas da alienação mental no Rio de Janeiro.

A $23^{\circ}$ do sul do equador, entre este e o Trópico do Capricórnio que o avizinha, encontramos o Rio de Janeiro, bem como o vasto império do Brasil, do qual é a capital. É um dos países mais quentes do planeta. Trata-se de um dado semiológico importante que deve ser levado em consideração desde o início, pois explica parcialmente o pequeno número de alienados no Império do Brasil, bem como a forma aguda que a loucura assume facilmente neles. Esquirol já havia relatado esse fato:

"Os climas quentes não são aqueles que produzem mais loucos, mas os climas temperados, sim." E mais adiante, falando da influência das estações sobre a loucura: "Hipócrates, Areteu e Celso garantem que o verão produz o furor". Essa ideia é retomada nessa outra sentença: "O calor como o frio agitam os alienados, mas com a diferença de que o calor contínuo aumenta a exaltação, enquanto o frio prolongado a reprime".

* Publicação original: Une visite à l'asile de Pedro II à Rio de Janeiro (Brésil). Par M. F. Jouin, Annales médico-psychologiques, ano 38, n. 3, p. 237-249, 1880 (na seção Estabelecimentos de Alienados). Tradução de Christian Greis. Revisão técnica e notas de Manoel Olavo Teixeira. 
A questão das raças humanas constitui também para nós um dado semiológico de extrema importância do ponto de vista da alienação mental, e sobre o qual os autores parecem não ter chamado suficientemente a atenção dos observadores.

Estas, variadas no Brasil, podem ser classificadas em quatro tipos principais:

A raça primitiva dos índios, que tende a desaparecer mais a cada dia e da qual encontramos apenas alguns representantes nos arredores da capital.

A raça conhecida como mamelucos ${ }^{1}$ ou simplesmente filhos do país que resulta da mistura dos conquistadores portugueses e das mulheres índias, conforme essa grande lei das conquistas: "Os recém-chegados matam os homens que lhes disputam a propriedade da terra e se casam com suas mulheres, o que resulta no nascimento de mestiços, que constituem uma nova raça".

No entanto, essa raça dos filhos do país, mais ou menos mista, mais ou menos modificada pelo contato com os europeus recém-chegados, constitui senão a maior parte da população, pelo menos a mais ativa e a mais honrada. Só ela produz os funcionários. É a ela que a classe alta do Rio de Janeiro se orgulha de pertencer. É uma raça muito bonita, pois ela é fortificada pela adição frequente de elementos heterogêneos, mas também é terrivelmente atingida pelo veneno orgânico que resulta na febre amarela.

A raça negra, da África, conta no Rio de Janeiro e nos seus arredores com uma grande quantidade de representantes. É ela que fornecia os escravos. Logo completamente liberta, ela permanece no país, onde constitui talvez a metade da população.

Por fim, a raça europeia, composta de franceses, belgas, alemães e principalmente de portugueses.

Estendemo-nos propositadamente sobre a enumeração dessas diferentes raças, embora os autores clássicos tenham mencionado essa questão apenas de maneira incidental. De fato, para Esquirol, é a própria civilização e não a raça civilizada que causa o grande número de alienados nos povos mais cultos. A maioria dos autores compartilha dessa opinião, como Guislain, Williams e Humboldt (porém, o Dr. Williams fez as suas observações na China, que é certamente um país tão civilizado, pelo menos nas cidades, quanto muitos dos nossos departamentos). Da mesma maneira, as observações de Guislain se baseiam em estatísticas de Alexandria e Jerusalém, grandes centros nos quais a luta pela vida se torna às vezes muito difícil, onde a sensibilidade certamente encontra muito mais alimentos que a exaltam e a sobreexcitam do que nos nossos campos plácidos da França e que são, no entanto, mais sujeitos à alienação mental.

1. "Mamalucos", no original. (N. do R.)

Rev. Latinoam. Psicopat. Fund., São Paulo, v. 15, n. 2, p. 404-412, junho 2012 
Portanto, há aqui um desideratum científico que certamente não conseguiremos preencher, mas para o qual gostaríamos de chamar a atenção.

Antes de discursar sobre os pacientes do asilo de Pedro II, segue uma breve descrição sobre o próprio edifício.

Quando, ao deixar o oceano Atlântico, o navio passa pela garganta estreita e pitoresca que constitui a entrada da baía do Rio de Janeiro, dois fortes impressionantes, um no sul e um no norte, aparecem à primeira vista. Depois de ultrapassá-los, a paisagem se abre de ambos os lados desenhando duas curvas majestosas e regulares que se reencontram no fundo da baía. À esquerda, no sul, vê-se primeiro a escola militar. À direita, no norte, a estância balneária do Brasil, a "Trouville" do Rio de Janeiro. Essa cidade pitoresca, localizada no fundo da baía, um pouco à esquerda, aparece toda cintilante sob o céu bonito dessas regiões feéricas do sol, com seus edifícios portugueses, suas igrejas mouriscas, seu porto repleto de navios.

$\mathrm{O}$ asilo dos alienados foi construído às margens do porto, entre o forte do sul e a cidade, antes dela e depois do forte e da escola militar, ao lado da qual ele se encontra. A sua vista do navio é a mais graciosa, a mais pitoresca possível para um estabelecimento desse tipo. É nesse lugar, na frente dessa natureza majestosa, de frente para a mais bela baía do mundo, que se passa a vida dos pobres alienados que ele abriga. No norte, a baía, os navios da frota brasileira, o movimento permanente do porto, de modo que dos seus quartos, os pacientes podem ver, saudados pelos canhões dos fortes, os navios de todas as nações do mundo entrar e sair, assistir aos espetáculos marítimos de um povo jovem, entusiasta e sempre em festa.

Ao sul, o Corcovado, graciosa montanha conhecida pelos caminhantes do Rio de Janeiro, toda coberta pela vegetação luxuriante dos países tropicais, adornada com palmeiras gigantes, com seus laranjais, os seus cactos gigantes.

À direita, o mar. À esquerda, no primeiro plano, o Rio de Janeiro e para além do horizonte, a Tijuca e Petrópolis.

É claro que se, como já foi dito, os grandes espetáculos da natureza conseguem modificar de maneira vantajosa os distúrbios da inteligência, o asilo do Rio de Janeiro não deixa nada a desejar em termos de sua localização.

Quanto à sua construção e à distribuição de suas diversas áreas, elas também nos pareceram notáveis. Vasto, espaçoso, o edifício é dividido pela capela e pela comunidade em duas partes aproximadamente iguais. A ala esquerda é ocupada pelas mulheres, a direita é reservada aos homens. Penetra-se no asilo por uma

2. Os relatos de Jouin e Rey estão em desacordo quanto à localização das alas do Hospício de Pedro II. A descrição correta é a de François Jouin. De acordo com Moreira de Azevedo (1969) "o lado direito do edifício é ocupado pelos homens, e o esquerdo pelas mulheres" (p. 473). Pedro Calmon, em O palácio da Praia Vermelha (1952) também confirma esta descrição. (N.da R.) 
porta graciosa e ao mesmo tempo monumental que certamente não foi feita para inspirar medo aos pacientes que chegam. No saguão, no qual se chega primeiro, há duas estátuas de bronze. Lemos, nas suas bases, com uma emoção muito natural, a 1.800 léguas da França, o nome dos nossos dois grandes alienistas: Pinel e Esquirol.

Do saguão, passamos para a sala de espera, onde logo se junta a nós o Dr. Gustavo Balduíno de Moura e Câmara, ${ }^{3}$ o médico-chefe do asilo, ao qual conferimos aqui com muita alegria os nossos mais sinceros agradecimentos pela grande complacência com a qual ele guiou a nossa visita e satisfez a nossa curiosidade sobre tudo que diz respeito à casa.

Ao contrário do que geralmente é observado na França, o asilo do Rio de Janeiro destina-se para receber tanto as pessoas as mais ricas, bem como os mais pobres escravos. ${ }^{4}$

Como resultado, os pacientes são materialmente e administrativamente distribuídos em duas grandes categorias, os indigentes e os pensionistas.

São considerados indigentes:

1. As pessoas pobres do império;

2. Os escravos de pessoas pobres;

3. Os marinheiros em condições administrativas correspondentes.

Quanto aos ricos e seus escravos, eles são apenas aceitos como pensionistas de primeira, segunda ou terceira classe, conforme sua fortuna. Para ser aceito na primeira classe, deve-se pagar uma quantia anual de 5.000 francos - que é de 3.800 na segunda classe - e finalmente, 2.500 ou apenas 1.700 na terceira classe, dependendo da pessoa ser livre ou escrava. Nesse último caso, é preciso dizer que a assistência pública obriga os donos dos escravos a arcar com a quantia.

A divisão dos alienados em três classes explica a falta de simetria na distribuição das várias salas da casa. Os alienados de primeira classe moram em quartos particulares, os pacientes de segunda classe ocupam um quarto duplo e os outros são hospedados em dormitórios.

O que impressiona à primeira vista é a extrema limpeza de todas as áreas do edifício e a distribuição essencialmente higiênica e bem adequada das diferentes salas. Há refeitórios grandes, dormitórios perfeitamente ventilados e os tetos são muito altos, o que confere a todas as salas o maior espaço possível.

3. “Gustave Balduino de Noura e Camera", no texto original. Diretor-médico do hospício de Pedro II de 1877 a 1881 . (N. do R.)

4. O Decreto Imperial de 18 de julho de 1841 determina a criação do Hospício D. Pedro II para o tratamento e a cura dos alienados de ambos os sexos de todo o Império, sem distinção de condição, nacionalidade e religião. (N. do A.) 
Não vamos nos alongar sobre esses detalhes, os arquitetos do edifício se inspiraram evidentemente nas casas da Europa do mesmo tipo para a construção de suas diferentes áreas. No entanto, notamos alguns detalhes que são originais. Assim, não vimos, em nenhum outro lugar, pátios tão bem dispostos para conter os agitados como no asilo D. Pedro. Grandes, localizados no centro de cada divisão, sob o piso térreo para que os pacientes não possam sair, são dois tipos de fossas, mas grandes, limpas e muito bonitas, nas quais os agitados e os maníacos permanecem durante o dia. Essa medida foi tomada para facilitar o seu monitoramento. Assim, um único guarda basta para controlá-los todos simultaneamente, em tempo integral.

Devemos acrescentar que cada recinto foi construído com um cuidado tão especial que parece, às vezes, exagero. Assim, até as celas acolchoadas são construídas com uma perfeição incrível. Tudo foi previsto: os cantos são protegidos por espuma, as paredes são acolchoadas e, para sair, o louco furioso deve quebrar duas portas dispostas de modo que não pode nem danificá-las, nem utilizá-las como armas contra si mesmo. No entanto, a camisa de força não foi eliminada: ela é de fato utilizada raramente, mas quando o paciente está agitado demais, ela é aplicada. Porém, apenas o médico-chefe tem o direito de ordenar o seu uso.

Obviamente, os custos não foram levados em consideração para construir o asilo D. Pedro. Assim, tudo não é apenas limpo e bem disposto, mas ainda suntuoso e belo. Não vimos, no Rio de Janeiro, nenhuma outra sala mais rica, mais luxuosa, que a sala do asilo destinada a receber o soberano.

Revestida de veludo, ela é adornada com estátuas de mármore representando as grandes personagens do Brasil e os principais alienistas do país. Dois tronos permanecem à disposição dos soberanos, que se orgulham muito, como se sabe, do seu asilo D. Pedro, que o visitam com frequência para avaliar, com seus próprios olhos, possíveis mudanças necessárias.

Notamos ainda no sul da casa, além do imenso jardim, no declive do pitoresco Corcovado, uma pequena fazenda em construção que nos fez visitar orgulhosamente o Dr. Moura e Câmara. ${ }^{5}$ De fato, ele acabara de obtê-la do governo para que seus pacientes pudessem trabalhar nela. Muito confiante no tratamento moral da loucura, o que ele repetiu várias vezes, ele pretende obter, por meio desses trabalhos de campo, resultados melhores.

Concluímos essas considerações de ordem material dizendo que os alimentos dados a todos os pacientes são excelentes, como pudemos verificar pessoalmente ao visitar as cozinhas na hora do almoço.

Visitamos o edifício. Falaremos agora dos alienados. A população do asilo Pedro II varia entre 330 e 350 pacientes. Entretanto, esse asilo é o único que existe

5. "De Noura e Camera", no original (N. do R.)

Rev. Latinoam. Psicopat. Fund., São Paulo, v. 15, n. 2, p. 404-412, junho 2012 
por todo o Império do Brasil e, como sabemos, o Brasil possui quase 15 milhões de habitantes.

É verdade que as relações com o centro do Império, com as cidades muito afastadas são bastante difíceis, que muitos alienados são, portanto, forçados a permanecerem em suas respectivas regiões. Mas não deixa de ser surpreendente ter uma quantidade tão pequena de alienados em uma cidade de 500.000 habitantes, tendo em vista a comunicação fácil com a Bahia, o Pernambuco e alguns outros grandes centros que enviam seus pacientes para o asilo. Seria a influência do calor tão marcante ou vemos aqui, antes de tudo, a influência da raça?

Embora aceitemos em parte a primeira causa, preferimos a segunda hipótese que, para nós, tem em seu favor as seguintes considerações: uma coisa nos impressionou especialmente ao entrar nas enfermarias: a baixa quantidade de negros. Numa cidade onde eles constituem, como dissemos, metade da população, ficamos muito surpresos de não encontrar mais de um deles em cada sete ou oito pacientes.

Além disso, esses negros estavam sofrendo de idiotia, de desenvolvimento intelectual interrompido, em vez de a própria loucura. Vimos apenas um negro maníaco. Certamente havia vários no asilo, mas repetimos que só vimos um. Não temos documentação sobre esse assunto, lamentamos não poder dar aos nossos pensamentos toda a precisão necessária.

Afirmamos que o número de negros que se tornaram loucos é muito limitado, no asilo D. Pedro, e se a nossa afirmação é verdadeira para os homens, ela o é muito mais para as mulheres que, se desconsideramos algumas idiotas, pertencem principalmente à raça dos filhos do país e à emigração europeia.

Mas isso não é tudo. Não encontramos nenhum representante da raça indígena no asilo, absolutamente nenhum. É verdade que as relações entre os habitantes primitivos e os conquistadores são muitas vezes tensas e difíceis, o que pode em parte explicar essa aparente imunidade da raça amarela. No entanto, existe um número bastante grande de tribos submetidas que estão em contato com a capital e que vivem nos arredores do Rio de Janeiro, o que faz com que essa imunidade nos pareça, no mínimo, surpreendente.

Concluímos e confirmamos esses dois fatos afirmando que até a quantidade de filhos do país, os mestiços, que resultam da mistura de portugueses e de mulheres indígenas, é relativamente baixa, no asilo. A maioria de sua população consiste de fato de europeus recém-chegados, ou de cariocas de segunda, terceira ou, no máximo, quarta geração.

Esta característica tríplice tão notável despertou muito a nossa curiosidade. Ouvimos muitas vezes o nosso venerável mestre, Moreau (de Tours) afirmar o quanto os alienados são raros nos países mais ou menos selvagens e sabíamos que, durante suas longas viagens, ele não tinha encontrado um único louco em toda a Núbia. 
Por outro lado, conhecemos as opiniões de Esquirol sobre o papel da civilização na etiologia da loucura. Mas, essas opiniões, numa cidade onde todas as raças vivem a mesma vida, lutam pela sobrevivência um ao lado do outro, com a mesma tenacidade, o mesmo ardor, são afetadas de maneira tão desproporcional, essas opiniões que relacionam a loucura ao nervosismo e à ambição engendrados pelos centros civilizados, não bastem mais para a nossa avaliação e para explicar o que observamos. Portanto, cremos que seja necessário mudar de opinião e desenvolver ideias novas e totalmente diferentes daquelas que havíamos aceitado até agora para elucidar essa questão.

Em Montevidéu e Buenos Aires, muitos outros fatos conclusivos corroboram o que já havíamos observado no Rio de Janeiro.

Cremos, portanto, ter o direito de afirmar hoje que há na etiologia antiga da loucura um elemento sobre o qual os autores clássicos não insistiram o suficiente, o elemento da raça. Esse explica bem melhor que o argumento da civilização as observações de Guislain, de Williams, de Moreau (de Tours) e os fatos que de outra maneira não poderiam ser explicados e que observamos pessoalmente num meio especialmente favorável ao estudo desse ponto da etiologia mental.

Mas, vamos dar continuidade à análise dos alienados do asilo D. Pedro. Mencionamos acima as fossas nas quais os agitados e maníacos permanecem durante o dia. Esses são, de fato, muito numerosos, no asilo, o que está relacionado com as opiniões de Esquirol, segundo o qual o calor confere à loucura uma exaltação altamente pronunciada.

Assim, de $1^{\circ}$ de julho a 31 de dezembro, dos 203 homens alienados que eram internados no asilo D. Pedro:

141 sofriam de mania (depressiva ou expansiva, aguda ou crônica);

7 de mania de forma dupla;

20 de demência;

6 de paralisia geral;

9 de epilepsia;

7 de imbecilidade;

10 de afecções diversas;

3 de doenças não diagnosticadas. ${ }^{6}$

No entanto, apesar da incerteza que esses números geram, várias considerações se impõem:

1. A grande quantidade de maníacos, a respeito dos quais infelizmente não podemos dar explicações mais precisas.

6. Lamentamos não poder fornecer uma tabela análoga para a seção das mulheres. (N. do A.) 
2. E, por outro lado, a baixa quantidade de paralíticos gerais. No que diz respeito a eles, voltamos novamente à questão da raça, como explicamos acima: a maior parte dos paralíticos gerais, com os quais conversamos no asilo D. Pedro, são de fato europeus ou descendentes de europeus recém-chegados.

Sabemos que essas estatísticas possuem apenas um valor muito relativo. A organização hospitalar no Rio de Janeiro não há nada em comum com o que observamos em Paris e não pode ser comparada com a de Sainte-Anne, por exemplo. Esse fato é amargamente criticado pelo Dr. Moura e Câmara no seu último relatório anual, pois não há, além dessa casa (traduzo literalmente seu discurso), "nenhum Bicêtre, nenhuma Salpêtrière, nenhum Vaucluse, nenhum Ville-Evrard etc., para os quais poderia enviar seus crônicos", o que também não permite compará-lo com a organização da Salpêtrière, que conhecemos de maneira bem detalhada.

No entanto, a necessidade dos médicos do asilo D. Pedro em manter os seus doentes crônicos confere uma importância ainda maior a essa observação: nos países quentes, os agitados são muito mais numerosos do que nos climas temperados.

Além disso, a curabilidade da loucura também parece ser maior no Rio de Janeiro do que em Paris. Infelizmente, não podemos fornecer números exatos a respeito, mas o Dr. Moura e Câmara nos informou que mais de dois terços dos alienados que são internados no asilo são curados ou morrem dentro de um período muito curto de tempo, pois no Rio, muito mais frequentemente do que na França, as crises de mania aguda são fatais.

Esses são os detalhes médico-psicológicos que nos impressionaram de maneira especial durante a nossa visita ao asilo D. Pedro. Depois da descrição do edifício e dos doentes, concluiremos descrevendo a organização médica e administrativa da casa.

O asilo D. Pedro depende diretamente da Assistência pública. Apesar disso, permanece inacessível aos estudantes de medicina do Rio de Janeiro. O Dr. Moura e Câmara, que acompanha as notícias francesas com a maior atenção, lamenta profundamente essa situação e aguarda impacientemente o momento em que um curso clínico sobre a alienação mental será implementado no asilo, "um curso igual ao de Ball", como ele mencionou.

A casa está sob a responsabilidade geral do diretor geral da Assistência pública, do provedor da Santa casa da Misericórdia.

Abaixo deste, o médico-chefe do asilo é também o seu diretor imediato.

A administração está sob a responsabilidade de três funcionários que estão supervisionados por ele: um ecônomo, um escriturário e um tesoureiro.

Dois médicos estão encarregados do tratamento dos pacientes, um para os homens e outro para as mulheres. Ambos contam com a ajuda de um médico 


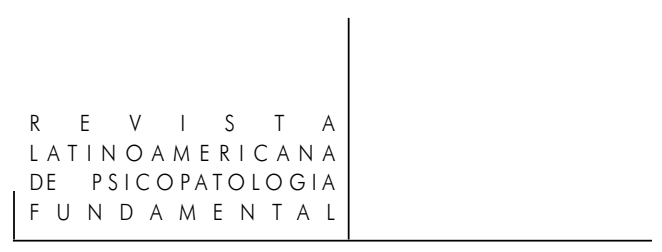

assistente. Além disso, há um médico especial e exclusivamente responsável pelo tratamento de doenças intercorrentes. Finalmente, um farmacêutico e seu assistente completam o serviço de saúde.

Freiras de São Vicente de Paulo, quase todas francesas, são responsáveis pelos cuidados extramédicos do atendimento, sob as ordens de uma superior que possui privilégios consideráveis e que ocupa no asilo uma posição bastante elevada.

Todos esses funcionários, o repetimos, estão sob a supervisão imediata do médico-chefe. Sendo assim, precisamos enfatizar o quanto é perfeito o funcionamento do asilo? Com que cuidado os pormenores da administração são levados em consideração?

Além disso, o Hospício D. Pedro é muito rico, pois ele é visitado com frequência pelo soberano e recebe muitos dos seus favores. Nenhum esforço é poupado para tornar a vida dos pobres pacientes mais agradável.

Assim, no caso de uma mulher afetada de megalomania simples que dizia ser a Imperatriz do Brasil, em lugar de contrariar seus delírios, improvisaram um trono com baldaquins decorados com bandeiras com as cores nacionais, onde ela recebia com muita dignidade as homenagens dos seus infelizes companheiros e dos visitantes do asilo. Essas medidas certamente não são nenhum meio de tratamento, nem mesmo moral, mas comprovam melhor do que qualquer discurso a simpatia e a doçura humana com as quais o Dr. Moura e Câmara ${ }^{7}$ trata seus pacientes.

7. "Noura e Camera", no original. (N. do R.)

\section{François Jouin (1854-1928)}

Médico interno dos hospitais de Paris; médico alienista e clínico geral; autor de diversos relatos de viagem. Entre seus trabalhos: "Visite à Pompei; Naples et la Sicile (stations thermales)" (1882); "Congrès International de Médecine de Londres (1882); "De la dilatation immédiate progressive" (1883); "Une promenade aux eaux" (1884); "Des différents types de métrites; leur traitment" (1892); "Bourg-le-Roi, journal d'une excursion archéologique dans l'histoire de France et du Maine" (1909). 